\title{
Monte Carlo Procedure to Evaluate the E-mobility Impact on the Electric Distribution Grid
}

\author{
S. M. Mirbagheri ${ }^{1}$, F. Bovera ${ }^{1}$, D. Falabretti ${ }^{1}$, M. Moncecchi ${ }^{1}$, M. Delfanti ${ }^{1}$, M. Fiori ${ }^{2}$, M. Merlo ${ }^{1}$ \\ ${ }^{1}$ Energy Department, Politecnico di Milano, Via La Masa 34, 20156, Milano, Italy \\ 2 ASSEM SpA, Loc. Colotto 11, 62027, San Severino Marche (MC), Italy \\ sayedehmina.mirbagheri@polimi.it
}

\begin{abstract}
The goal of this work is to evaluate the impact of the e-mobility charging processes on the electric grid, in a real-life study case. An effective approach is proposed to study the increase in the energy consumption on the grid with respect to both grid operation and efficiency. The work is developed considering three different recharging technologies, slow (based on domestic users), fast (based on public charging stations), and very fast (based on enhanced public charging stations). Furthermore, three different technologies distributions are evaluated (e.g. different scenarios on charging station deployment are simulated). The results show that fast charging technologies could better fit with e.cars exploitment, but they could cause also a significant stress increase over the grid. The paper is devoted to quantify such effects.
\end{abstract}

Index Terms-hosting capacity, e-mobility, Monte Carlo, San Severino Marche, inteGRIDy.

\section{INTRODUCTION}

Nowadays, Renewable Energy Sources (RES) are the main driver of the ongoing energy revolution all over the world. In order to manage RES, electric networks infrastructure, and the relevant regulatory and market frameworks, need to be properly updated. Similarly, there is a significant effort in the energy world toward a low carbon framework: one of the sectors which is experiencing important improvements is transportation. In 2011, the road transportation greenhouse gas emission was estimated $17 \%$ of the total $24 \%$ in the European Economic Area. Hence, European Commission has adopted a roadmap to cut $20 \%$ of transportation emission by 2030 and $60 \%$ by 2050 [1]-[3]. Therefore, transportation sector is shifting to electric mobility (e-mobility) and Electric Vehicles (EV) that could reduce the $\mathrm{CO} 2$ emissions [4]. Actually, it is particularly important to evaluate which role the electric mobility could play in the new framework of the RES based electric grids.

Electric mobility could act as an elastic load; it could theoretically change its energetic behavior in order to fit at best with the energy balance of the grid. It is well known that a first step of integration in the electric grid is relevant to a control of the charging processes, in order to schedule them at best [5] or to limit them in case of a grid congestion [6]. A second, more advanced, step is the so called vehicle-to-grid approach, that is, an active role of the e-mobility batteries injecting, when necessary, power to the grid, e.g. in case of a system under-frequency transients.
This paper is focused on the first step, i.e. the goal of the work is to evaluate the impact of the e-mobility charging processes on the distribution grid, in a real life study case, to manage the relevant increase in energy consumption with respect to both the grid operational and efficiency parameters.

In the literature, some research has been done focusing on EVs management to schedule the charge of EVs optimally. In [6]-[10] the day-ahead forecasting techniques of EV load have been used to minimize the energy cost or to maximize the operators profit by creating the charging process schedule. Heuristic approach based on particle swarm optimization is used in [11] to determine the allocation of EVs. In this study, the power flow procedure is run before the optimization process. The possibility of discharging batteries to provide energy to the grid is evaluated in [9]. The offline optimization used in this research presents some limitations in terms of flexibility in the management of unexpected working conditions. The works in [7], [8] are based on online procedures. The method proposed in [7] uses the preliminary optimization that could define the set-point for each charging station. Moreover, a controller implemented in the charging station schedules the Charge Requests (CRs). The station triggers an update of the set-point, if it cannot be met. The network operation effects on the CRs constraints, and the advantages of the scheduling procedure on the power system, have not been studied in depth, as the infrastructure of electricity distribution is not modeled in this study. In [8], the power grid is divided in zones; the spatially distributed optimization procedure performed for each zone independently leads to local optima. For this reason, this method does not address network-wide issues and constraints.

Another important topic to be addressed evaluating the emobility evolution is relevant to the regulatory framework. In fact, charging stations could be classified in public and private points. In the first case, private users will have to activate two different supply contracts and two different meters; this could open to advanced energy price tariff focused on e-mobility. Similarly, private charging stations could be activated and managed for a public use; in this case the owner will act as an energy supplier, providing also additional services. In case of public charging points, it is mandatory to guarantee a nondiscriminatory access to the area; they could be managed by the Distribution System Operator (DSO) or, in order to 
foster competition, by new e-mobility operators. Investment cost could be covered by revenues on the access fees; incentive schemes could be proposed by the National Regulatory Authorities (NRA) in order to foster the e-mobility growth. Since this topic is particularly debated and worth an investigation, in the following a focus is dedicated to the regulatory framework evaluation.

\section{ITALIAN LEGISLATION FOR SUSTAINABLE MOBILITY}

The Italian legislation concerning the alternative fuels adopted in the transport sector evolved in the last decade moving from the acknowledgement and the adoption of European Directives, contextualized in the energy strategy EU2020 put in place by European Commission (EC). In particular, the strategy for Europe-2020 [12] promotes the diffusion of sustainable mobility looking after three main issues:

- the definition of common technical standards,

- the development of the required infrastructure and

- the incentivization of research in transport field.

More specifically, policies foreseen in Transport2050 [2] roadmap by EC define ambitious targets such as:

- a reduction of $\mathrm{CO} 2$ emissions from the transport sector by $60 \%$,

- a strong effort towards the usage of zero and low emissions Electric Vehicles (EV) and Hybrid Electric Vehicles (HEV) and

- the prevalent presence of ecological vehicles in urban areas.

Moreover, the Directive 2009/33/EC [13], concerning the promotion of green and low consumption vehicles, defined the target of $10 \%$ renewable energy quota in transport sector by 2020; these actions are included in a general framework where the diffusion of EV (and HEV) is promoted together with a continuous reduction of Green House Gases (GHG) emission by traditional, Internal Combustion Engine (ICE) based vehicles [14].

Following the 2020 package and the actions urged for the transport sector by EC, many associations have been called to express their position at European and national level; the relevant documents have been exploited to define policies to be implemented in Italy [15]-[18].

As a first result of the EU directives, since 2010 ARERA, the National Regulation Authority of Italy, sustained electrical mobility through a series of actions, with reference to both private charging systems and public ones. With the Decision 56/2010 [19] ARERA introduced a general system charge and a grid services tariff for private charging systems, deleting the legislative constraints that could impede the installation of new charging points; right after, with Decision 242/2010 [20], a new tariff for public charging systems has been introduced: this tariff entered in force in 2011 and is updated every three months. Within the same decision, ARERA launched a series of pilot projects concerning the development of infrastructures for the charging of $\mathrm{EV}$; these pilot projects have been selected with the Decision 96/2011 [21] and ended in 2015, bringing to relevant results.

More recently, the European and Italian legislation concerning the promotion of EV moved from two main measures:

- the EU Directive 2014/94/EU and

- the Law of 7 August 2012 n. 134 by the Italian Parliament.

Starting from the guidelines identified by the two documents at European and Italian level, it has been possible to define the deployment plans for EV charging infrastructures, the technical rules concerning modes and type of connections required for $\mathrm{EV}$ charging systems, and all regulatory aspects concerning the management of EV charging points.

On October 2014, European Parliament (EP) published the Directive 2014/94/EU [22] defining the main options for the diffusion of alternative fuels in the transport sector. The document individuated main obstacles for the diffusion of new mobility solutions in:

- the absence of a physical infrastructure for distribution of alternative fuels and

- the absence of a common reference framework concerning technical rules and standards.

These two issues are correlated to the lack of awareness regarding alternative fuels by EU citizens, the inability to develop economy of scale in this sector, in terms of both demand and offer of zero emissions vehicles.

Italy has acknowledged and applied the EU directive with the Law n.134 of August 2012, defining the development of a national charging infrastructure for EV as a priority among the actions to be implemented in the 2020 panorama. Under the light of this law, since 2013 Italy defined a national infrastructural plan for the charging of electric vehicles (known with the Italian acronym PNire [23]), furtherly developed with the Law of 16 December 2016 n.257 [24]. The plan defines the guidelines to establish a diffuse development of charging stations for EV all over the Italian territory, starting from a series of measures involving:

- the institution of an EV charging service, for both private and public transport, which is coherent with the EU framework;

- the introduction of management procedures for the services to be delivered in charging stations, particularly concerning the costs to be sustained by the users, the presence of a differentiated system tariffs and the regulation of modes, time and connections required for the charging process, taking care of the needs of users and of the electric grid;

- the introduction of incentives and facilitation for the operators of the charging stations to favor the updating of services offered;

- the realization of specific programs to promote the technological update of the existing private and public buildings, in order to integrate EV charging solutions;

- the promotion of research activities in all the fields concerning the development of new solutions for EV 
charging processes, and all the aspects related to sustainable mobility.

The PNire implementation has been divided into two different steps:

- phase 1 (2013-2016), where institutions are called to define a reference framework for the infrastructural development and implement a first technological deployment which can guarantee the EV motion within urban areas;

- phase 2 (2017-2020), where EU member states, stakeholders and national authorities are called to define harmonized standards to favor the diffusion of sustainable solutions, and charging infrastructure must be completed to host a high and increasing level of EV penetration.

According to EU directives, Italian legislation defined four main charging modes, differentiated on the basis of the power provided during charging process, and consequently the time needed to charge an EVs battery. This classification distinguishes slow, fast and very fast charging process, going from $7.4 \mathrm{~kW}$ of power provided (slow) up to more than $50 \mathrm{~kW}$ (very fast). The different technological solutions which can be adopted have been declined by Italian legislation according to different charging scenarios.

In the first scenario the charging process is supposed to last for a long time: this is the case of charging points at workplaces or in residential areas, where charging process is carried out during the whole day or at night-time. In this case low power $(7 \mathrm{~kW})$ charging points are required, and type 2 connection plugs are needed.

In the second scenario the charging process lasts for less than two hours, such as in the case of commercial areas where tertiary services are provided; therefore, medium power charging points are requested, with the possibility to charge more than one vehicle at the same time from a single charging station. The typical power provided is around $20 \mathrm{~kW}$.

In the third scenario the time foreseen for the charging process is reduced, typically below 30 minutes. In this case, high power solutions, both in $\mathrm{AC}$ and in $\mathrm{DC}$, are required, to guarantee flexibility and high performances; hence, advanced Combined Charging Systems (CCS) must be implemented. It is important to notice that in every case the charging process must be guaranteed independently from the necessity for the user to conclude a deal exclusively with the operators of charging stations; moreover, the provision of the charging process should be developed as the selling of a service and not of a good. Consequently, advanced solutions concerning the metering of energy provided, the monitoring of relevant parameters and the optimization of charging process can be a part of the service purchased by the user.

Finally, the realization of charging infrastructures must be carried out through proper agreements with the local administrations and the DSOs, in order to exploit the knowledge of the territorial needs and to verify the limits due to the electricity distribution grid.

\section{EVALUATION OF THE E-MOBILITY CHARGE PROCESSES IMPACT ON THE DISTRIBUTION GRID}

One of the biggest challenge for DSOs is the use of an intelligent control for managing power fluctuation due to passive and active users, to have more reliable and efficient networks [25]. In the DSO perspective, it is very important to guarantee a reliable management of the distribution grid, consequently proper planning and operational tools are required. Actually, the increasing of EV utilization may cause overload and undervoltage disturbances on the distribution grid [26], [27].

With respect to DGs, in the literature a lot of works propose a KPI approach, named Hosting Capacity [28], to evaluate the maximum amount of incremental generation the system can manage according to grid technical constraints (such as steady-state voltage variation, thermal limits and Rapid Voltage Changes RVC) [29]-[34]. On the other hand, increasing the end-user electricity requirements is the main issue from the demand side, which is leading to evaluate the operational margins [6].

In this paper a similar approach is proposed in order to evaluate the maximum amount of e-mobility charging processes the grid could manage. In particular, all the simulations are related to a real life grid: a MV distribution grid sited in the center of Italy (San Severino Marche), managed by the DSO A.S.S.E.M SpA. [35].

The KPI approach proposed for the evaluation of the emobility charging processes on the distribution grid is based on a Monte Carlo algorithm (MC). Scenarios are studied thanks to performance indices typically adopted for hosting capacity evaluation in [33], [36], [37].

\section{A. Steady-State Voltage Variations (SSV)}

In order to avoid malfunctions of grid connected equipment because of voltage increases sue to connected DG, the SSV variations, according to the EN 50160 [26], must remain within $\pm 10 \%$ of the rated voltage during $99 \%$ of the time [38].

$$
V_{\min , k} \leq V_{D G, k} \leq V_{\max , k}
$$

\section{B. Transformers and Lines Thermal Limits}

The generation exceeding the load causes reverse power flow. However, each branch of the network has a specific limit, depending on its own design and installation criteria.

$$
I_{D G, k j} \leq I_{\max , k j}
$$

\section{Rapid Voltage Changes (RVC)}

It is the difference between the voltage amplitude when DG is connected and injecting power into the grid and after its sudden disconnection. There is no strict constraint for RVC in EN 50160; only an approximate range of $4 \%$ to $6 \%$ of rated voltage is defined for MV networks.

$$
\left|V_{D G, k}-V_{k}\right| \leq 4 \% \div 6 \%
$$

where $V_{D G, k}$ and $V_{k}$ are the voltage amplitudes, respectively, with and without DG. 


\section{Grid Efficiency}

Losses on MV feeders can be evaluated as a further performance index; in particular such an index will be adopted to compare the efficiency of the electric grid in supporting different e.mobility penetration scenarios, and allows to compare each other the grid performances with respect to different assumptions in the e.mobility parameters.

In order to model e-mobility energy needs, the MC procedure developed is based on different assumptions. In the simulation performed, a charging station has been supposed in place in every secondary substation of the passive grid. In this regard, three different charging modes have been proposed, coherently with the scenarios detailed in section II. Namely, 3 $\mathrm{kW}$ (the most common solution in place in Italy for domestic and slow charging process), $20 \mathrm{~kW}$ (selected to represent fast public charging station) and $50 \mathrm{~kW}$ (a realistic, short/medium term assumption for very fast charging station) have been selected as slow, fast and very fast recharge processing respectively. Each charging station has the same probability to be selected, while a roulette wheel selection has been used in order to select the node where a new e.car is asking for a recharge.

A second roulette wheel has been adopted in order to choose the nominal power of each charging process, i.e. to simulate different charging technologies for different vehicles. Three different distributions of each mode have been considered; the first distribution has been tested for mainly slow domestic recharge process, the second one is mainly fast process and the last one is considered in prevalence very fast process. In the following, the probability of each technology has been mentioned.

- Simulation SET1: $80 \%$ slow $+10 \%$ fast $+10 \%$ vary fast

- Simulation SET2: $20 \%$ slow $+60 \%$ fast $+20 \%$ very fast.

- Simulation SET3: $10 \%$ slow $+10 \%$ fast $+80 \%$ very fast

Similarly, adopting a third roulette wheel, a different distribution of arrival-departure time has been modeled for each vehicle (i.e. different charging time). For each hour of the year, the algorithm simulates the charging processes (increasing them iteratively) and checks the KPI devoted to evaluating the quality of supply, up to a predefined operational limit. Simulations are defined with respect to different assumptions. The slow recharge process time is concentrated on late evening and each charging process will last for 7 hours $(21 \mathrm{kWh})$. In this charging process, only one recharge per car in each single day is allowed. A high probability for using fast recharge process in late morning and afternoon has been assumed; each charging process will last for 2 hours $(40 \mathrm{kWh})$ and (as domestic charging process) only one recharge per car in each single day is permissible. The very fast process time has more probability from 8 a.m. to 22 p.m., as the charging process will last only one single hour $(50 \mathrm{kWh})$; two recharge processes in each day could be done by each electric car. Table I represents the summary of time probability adopted for the study.
TABLE I

TIME DISTRIBUTION IN DIFFERENT CHARGING TECHNOLOGY

\begin{tabular}{|c|c|c|c|c|c|}
\hline $\begin{array}{c}\text { Charging } \\
\text { Mode }\end{array}$ & $\begin{array}{c}\text { Power } \\
\text { (kW) }\end{array}$ & \multicolumn{2}{|c|}{ Time Probability } & $\begin{array}{c}\text { Charging } \\
\text { Time (h) }\end{array}$ & $\begin{array}{c}\text { Daily Charge } \\
\text { (each car) }\end{array}$ \\
\hline Slow & 3 & $\begin{array}{c}12 \mathrm{am}-6 \mathrm{pm} \\
6 \mathrm{pm}-12 \mathrm{am}\end{array}$ & $\begin{array}{c}0.1 \\
1\end{array}$ & 7 & 1 \\
\hline Fast & 20 & $\begin{array}{c}12 \mathrm{am}-10 \mathrm{am} \\
10 \mathrm{am}-3 \mathrm{pm} \\
3 \mathrm{pm}-6 \mathrm{pm} \\
6 \mathrm{pm}-12 \mathrm{am}\end{array}$ & $\begin{array}{c}0.1 \\
1\end{array}$ & 2 & 1 \\
\hline Very Fast & 50 & $\begin{array}{c}8 \mathrm{am}-10 \mathrm{pm} \\
10 \mathrm{pm}-8 \mathrm{am}\end{array}$ & $\begin{array}{c}1 \\
0.1\end{array}$ & 1 & 2 \\
\hline
\end{tabular}

\section{STUDY CASE DESCRIPTION}

San Severino Marche, with $193 \mathrm{~km}^{2}$ area, is a small town in the center of Italy; its $20 \mathrm{kV}$ distribution grid has a total length of $180 \mathrm{~km}$. Fig 1 shows the energy demand during a year, simulated in this paper exploiting the realistic assumptions on the load. Two transformers are placed in the primary substation; six feeders depart from one transformer and seven from the other one. In the past, the area reported a significant amount of hydro resources while, recently, photovoltaic penetration rises year after year. Moreover, due to the agricultural activities, good opportunities are also related to biomasses. The energy needs of the loads are quite limited, consequently a reverse power flow regularly occurs, especially during summer time.

Thanks to past experimental projects, the area is already provided with an advanced communication architecture, allowing the exchange of real-time signals/data between the DSOs control center and the users; the communication system is based on fiber optic, Wi-Fi bridges, and mobile network (LTE). Moreover, the smart grid core unit is linked to the DSOs SCADA/DMS and to a set of monitoring apparatuses deployed in primary and secondary substations to properly collect real time measurements about the grid operation [39]. Finally, weather nowcast and forecast equipment is going to be deployed in order to estimate in real time and in advance RES production [40].

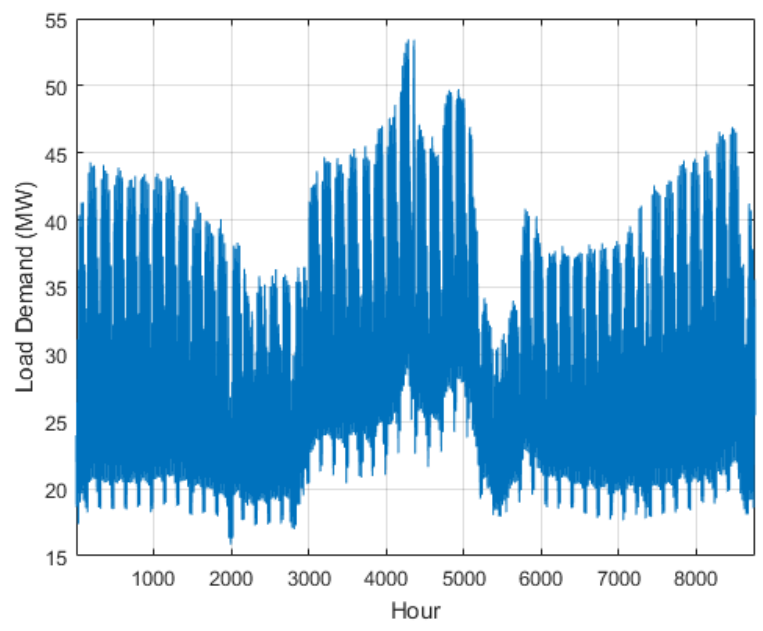

Fig. 1. San Severino energy demand (1 hour samples over a year). 
TABLE II

MONTE CARLO RESUlTS FOR 3 DIFFERENT RECHARGE PROCESSING DISTRIBUTION.

\begin{tabular}{|l|l|c|c|c|c|c|c|c|}
\hline \multicolumn{2}{|c|}{ Test Case } & \multicolumn{2}{c|}{ Voltage (pu.) } & \multicolumn{2}{c|}{ Thermal Limit (I/I $\max$ ) } & \multicolumn{2}{c|}{ RVC (pu.) } & Losses/Energy (\%) \\
\cline { 3 - 9 } & Min & Mean & Mean & Max & Mean & Max & Mean \\
\hline \multirow{3}{*}{ Simulation SET1 } & 1000 Cars & 0.9858 & 0.9966 & 0.0485 & 0.6221 & $1.1 \mathrm{e}-4$ & $1.08 \mathrm{e}-3$ & \\
& 2000 Cars & 0.9764 & 0.9954 & 0.0623 & 0.7781 & $2.3 \mathrm{e}-4$ & $2.17 \mathrm{e}-3$ & 0.84 \\
& 3000 Cars & 0.9728 & 0.9943 & 0.0763 & 0.9682 & $3.4 \mathrm{e}-4$ & $2.49 \mathrm{e}-3$ & 0.98 \\
& 4000 Cars & 0.9669 & 0.9932 & 0.0903 & $\mathbf{1 . 1 4 9 4}$ & $4.5 \mathrm{e}-4$ & $3.12 \mathrm{e}-3$ & 1.15 \\
\multirow{2}{*}{ Simulation SET2 } & 1000 Cars & 0.9831 & 0.9959 & 0.0564 & 0.7369 & $1.8 \mathrm{e}-4$ & $1.53 \mathrm{e}-3$ & \\
& 2000 Cars & 0.9585 & 0.9928 & 0.1002 & $\mathbf{1 . 2 0 8 1}$ & $5.3 \mathrm{e}-4$ & $3.94 \mathrm{e}-3$ & 0.95 \\
\multirow{2}{*}{ Simulation SET3 } & 1000 Cars & 0.9665 & 0.9955 & 0.0717 & 0.9964 & $3.2 \mathrm{e}-4$ & $3.16 \mathrm{e}-3$ & 1.27 \\
& 2000 Cars & 0.9497 & 0.9913 & 0.1131 & $\mathbf{1 . 4 7 3 7}$ & $6.4 \mathrm{e}-4$ & $4.87 \mathrm{e}-3$ & 1.24 \\
\end{tabular}

\section{SIMULATION AND RESULTS}

In order to validate the procedure proposed in section III, it has been tested an equivalent model of the San Severino distribution grid, and several simulations have been performed. In particular, for each single simulation set, the number of 1000, 2000, 3000 and 4000 electric cars have been connected to the grid nodes.

In the following a detailed analysis of the aforementioned simulations is reported; results are relevant to a whole year scenario and samples are detailed for each single hour. The focus is in the evaluation of the distribution grid hosting capacity in front of e-mobility and in the quantification of the relevant impact on losses. Scenarios simulated are detailed with respect to different assumptions on the e-mobility penetration in the area (power absorbed during the charge processes, number of charges in a day, travel length average, etc.).

After performing MC simulation for the mentioned number of cars and for each simulation set, the results were evaluated according to the technical constraints; Table II represents these results. For each simulation set Hosting Capacity limits are reported: min voltage steady state, max current over the feeders, rapid voltage changes and yearly losses over lines. According to this table, we can conclude that the hosting capacity of connecting electric cars to San Severino Marche grid is less than 4000, 2000 and 2000 cars for simulation SET1, SET2 and SET3 respectively. Actually, the table reports the KPI analysis up to the identification of an index violation. In all the simulations performed, the limiting factor results to be the maximum current over the grid branches. Based on the classified assumptions in the Simulation SET1 (charging processes mainly based on domestic and slow processes) the grid under study shows an overcurrent equal to $114.94 \%$ of the nominal one in managing 4000 e.cars. Adopting assumption corresponding to the Simulation SET2 (charging processes mainly base on fast public charging station) the hosting capacity is limited to less than 2000 cars (overcurrent up to $120.81 \%$ are detected). Finally, Simulation SET3 assumption drives to an even higher overcurrent, depicting a grid hosting capacity slightly higher than 1000 e.cars. Moreover, faster charging process could bring increase of system losses.

Figure 2 shows the transformer power flow after adding 1000 cars in the grid for each simulation set. As obvious, the power flow increased where the charging process is faster. In particular, this magnifies the total load for one week. It can
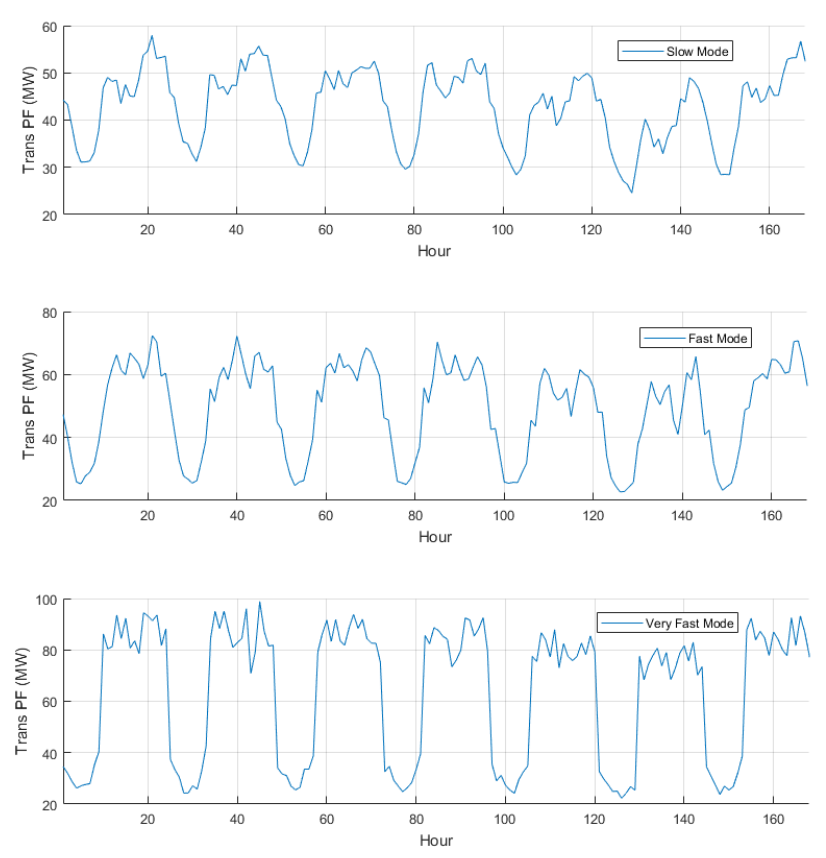

Fig. 2. Transformer power flow by connecting 1000 cars for different testing mode in one week.

be seen that, in simulation SET1 and SET2, the peak values could be changed in hours of the day by high probability of charging cars; however in simulation SET3 the peak values are focused in daylight hours, that is critical load fluctuation over a single day could arise (such a result is coherent with respect to the assumptions adopted in the models developed for this study).

\section{CONCLUSION}

The aim of this paper was to evaluate the impact of the e-mobility charging processes on the electric grid, in a real-life study case. The study was developed according to three different recharging modes, the first based on domestic charging process, the second relevant to public fast charging station, the latter based on enhanced, very fast, public charging stations. Afterwards, three different test case (SET1, SET2 and SET3) had been tested. The charging processes impact on the grid has been evaluated adopting a KPI procedure, devoted to quantify the hosting capacity of the grid. In all the 
simulations performed, no criticalities have been detected with respect to the feeders voltage profile. As a matter of fact, the limiting factor in the grid charging process hosting capacity resulted to be the line thermal limit, i.e. the maximum current the feeders could manage. In addition, the results showed that although SET3 distribution (mainly very fast charging) provides high speed charging process, it could cause some critical load fluctuation over a single day limiting the capacity of the grid to host recharge process, or, similarly, decreasing the efficiency of the distribution grid.

\section{REFERENCES}

[1] Vicente, A. S., Laying the foundations for greener transport. TERM 2011: Transport indicators tracking progress towards environmental targets in Europe, EEA Report 7/2011., European Environment Agency: Copenhagen, Denmark, 2011.

[2] European Comission. Directorate-General for Mobility and Transport, Roadmap to a Single European Transport AreaTowards a Competitive and Resource Efficient Transport System, Brussels, Belgium, 2011. Available from: eur-lex.europa.eu.

[3] G. Benetti, M. Delfanti, T. Facchinetti, D. Falabretti, and M. Merlo, Real-time modeling and control of electric vehicles charging processes, IEEE Transactions on Smart Grid, 2015, 1375-1385.

[4] Eur. Fed., Europes cars? An Analysis of Carmaker Progress Towards EU CO2 Targets in 2009, Transport Environment., Brussels, Belgium, 2011.

[5] J. A. P. Lopes, F. J. Soares, and P. M. R. Almeida, Integration of electric vehicles in the electric power system, Proceedings of the IEEE 99.1, 2011: 168-183.

[6] O. Sundstrom and C. Binding, Flexible charging optimization for electric vehicles considering distribution grid constraints, IEEE Trans. Smart Grid, vol. 3, no. 1, pp. 2637, Mar. 2012.

[7] K. De Craemer, S. Vandael, B. Claessens, and G. Deconinck, An eventdriven dual coordination mechanism for demand side management of PHEVs, IEEE Trans. Smart Grid, vol. 5, no. 2, pp. 751760, Jul. 2013.

[8] Y. He, B. Venkatesh, and L. Guan, Optimal scheduling for charging and discharging of electric vehicles, IEEE Trans. Smart Grid, vol. 3, no. 3, pp. 10951105 , Sep. 2012

[9] E. Sortomme and M. El-Sharkawi, Optimal scheduling of vehicle-togrid energy and ancillary services, IEEE Trans. Smart Grid, vol. 3, no. 1, pp. 351359, Mar. 2012.

[10] A. Al-Awami and E. Sortomme, Coordinating vehicle-to- grid services with energy trading, IEEE Trans. Smart Grid, vol. 3, no. 1, pp. 453462, Mar. 2012.

[11] J. Soares, H. Morais, T. Sousa, Z. Vale, and P. Faria, Day-aheadresource scheduling including demand response for electric vehicles, IEEE Trans. Smart Grid, vol. 4, no. 1, pp. 596605, Mar. 2013.

[12] European Commision, A strategy for smart, sustainable and inclusive growth, March 2010. Available from: eur-lex.europa.eu.

[13] European Parliament and Council, Directive 2009/33/CE on the promotion of clean and energy-efficient road transport vehicles, April 2009. Available from: eur-lex.europa.eu.

[14] European Commission, CARS 2020: for a strong, competitive and sustainable European car industry, November 2012. Available from: europa.eu.

[15] European Automobile Manufactures Association, ACEA position and recommendations for the standardization of the charging of electrically chargeable vehicles, May 2012. Available from: acea.be

[16] EURELECTRIC, Facilitating e-mobility: EURELECTRIC views on charging infrastructure, March 2012. Available from: eurelectric.org.

[17] EURELECTRIC, Deploying publicly accessible charging infrastructure for electric vehicles: how to organize the market?, July 2013. Available from: eurelectric.org.

[18] CEI-CIVES, Position Papersul sostegno alla mobilit stradale sostenibile con veicoli a tecnologia elettrica, December 2012. Available (in Italian) from: cives.ceinorme.it.

[19] ARERA, Disposizioni in materia di connessioni per lalimentazione di pompe di calore a uso domestico e di veicoli elettrici, Decision ARG/elt 56/10. April 2010. Available (in Italian) from: arera.it.
[20] ARERA, Disposizioni speciali per lerogazione dei servizi di trasmissione, distribuzione e misura e del servizio di dispacciamento ai fini della sperimentazione dei sistemi di bassa tensione di ricarica pubblica dei veicoli elettrici, Decision ARG/elt 242/10. December 2010. Available (in Italian) from: arera.it.

[21] ARERA, Selezione dei progetti piltota di ricarica pubblica di veicoli elettrici, di cui alla deliberazione dellAutorit per lenergia elettrica e il gas, (now ARERA) 15 Dicembre 2010 ARG/elt 242/10, Decision ARG/elt 96/11. July 2011. Available (in Italian) from: arera.it.

[22] European Parliament and Council, Directive 2014/94/EU on the deployment of alternative fuels infrastructure, October 2014. Available from: eur-lex.europa.eu.

[23] Ministero delle Infrastrutture e dei Trasporti (MIT), Piano Nazionale Infrastrutturale per la Ricarica dei veicoli alimentati ad energia Elettrica, PNire, June 2016. Available (in Italian) from: governo.it.

[24] Il Presidente della Repubblica e il Consiglio dei Ministri, Decreto Legislativo 16 Dicembre 2016 n. 257, December 2016. Available (in Italian) from: gazzettaufficiale.it

[25] Eur. Reg., The Drive Towards Smart Grids: A Fact Sheet by the European Energy Regulators on How the Drive Towards Smarter Grids can Help Meet European Policy Objectives on Energy and Climate Change and Empower Customers, Council Eur. Energy Reg. (CEER), Group Electricity Gas (ERGEG), Brussels, Belgium, Oct. 2010.

[26] L. Pieltain Fernndez, T. Romn, R. Cossent, C. Domingo, and P. Fras, Assessment of the impact of plug-in electric vehicles on distribution networks, IEEE Trans. Power Syst., vol. 26, no. 1, pp. 206213, Feb. 2011.

[27] S. Shafiee, M. Fotuhi-Firuzabad, and M. Rastegar, Investigating the impacts of plug-in hybrid electric vehicles on power distribution systems, IEEE Trans. Smart Grid, vol. 4, no. 3, pp. 13511360, Sep. 2013.

[28] C. Schwaegerl, M. H. J. Bollen, K. Karoui, and A. Yagmur, Voltage control in distribution systems as a limitation of the hosting capacity for distributed energy resources, IET CIRED conference, 2005.

[29] Italian Legislative Decree 16 March 1999, n. 79, Application of Directive 96/92/CE, Containing Common Regulations for the Internal Market of the Electricity, Italian Parliament, Rome, Italy, Mar. 1999.

[30] Code for the Terms and Conditions for Electricity Grid Connection With the Obligation to Connect Third Party Electricity Generation Plants (Code for Active ConnectionsTICA), 2008. [Online]. Available: http://www.autorita.energia.it.

[31] M. H. J. Bollen and M. Hger, Power quality: Interaction between distributed generation, the grid and other customers, Elect. Power Qual. Utilisation Mag., vol. 1, no. 1, pp. 5161, 2005.

[32] J. Deuse, S. Grenard, K. Karoui, O. Samuelsson, L. Gertmar, P. Karlsson, et al. , Interactions of dispersed energy resources with power system in normal and emergency conditions, in Proc. CIGRE Int. Conf.Large Elect. Syst., Paris, France, 2006, pp. 112.

[33] D. Bertini, D. Falabretti, M. Merlo, D. Moneta, and J. S. D. A. Carneiro, Hosting capacity of Italian LV distribution networks, in 21st International Conference on Electricity Distribution, 2011.

[34] M. Merlo, N. Scordino, and F. Zanellini, Optimal power flow approach to manage dispersed generation rise and passive load energy needs over a distribution grid, Int. Rev. Elect. Eng., vol. 8, no. 5, pp. 14821494, 2013.

[35] https://www.assemspa.it/.

[36] M. Delfanti, M. Merlo, G. Monfredini, V. Olivieri, M. Pozzi, and A. Silvestri, Hosting dispersed generation on Italian MV networks: Towards smart grids, in Harmonics and Quality of Power (ICHQP), 2010 14th International Conference on, 2010, pp. 1-6.

[37] M. Mirbagheri, M. Moncecchi, D. Falabretti, M.Merlo, Hosting Capacity Evaluation in Networks with Parameters Uncertainties, in 18th International Conference on Harmonics and Quality of Power, 2018.

[38] Technical Standard EN 50160, CENELEC, Voltage characteristics of electricity supplied by public distribution systems.

[39] M. Delfanti, D. Falabretti, M. Fiori, M. Merlo, Smart Grid on field application in the Italian framework: The A.S.SE.M. project, Electric Power System Research, Volume 120, March 2015, 10.1016/j.epsr.2014.09.016.

[40] J. Soares, H. Morais, T. Sousa, Z. Vale, and P. Faria, Day-ahead resource scheduling including demand response for electric vehicles, IEEE Trans. Smart Grid, vol. 4, no. 1, pp. 596605, Mar. 2013. 